\section{Allergener Dampf}

— ine Patientin litt zweimal in der ten, Thoraxenge, Fieber und Abgeschlagenheit. Bei normalem physikalischen Lungenbefund und unauffälligem Röntgen-Thorax ergab die langwierige Diagnostik eine exogen-allergische Alveolitis (EAA). Die Frau hatte jeweils vor ihren rezidivierenden Symptomen mit einem Dampfbügeleisen gebügelt. Als Antigen wurde ein Bakterium aus der Flavobakterium/Cytophaga-Gruppe identifiziert, welches bisher

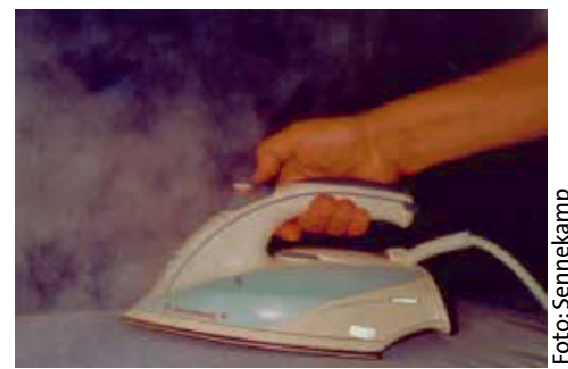

noch nicht als EAA-Antigen bekannt war. Prof. Dr. Joachim Sennekamp, Bonn

Rolke $M$ et al. 12. Tagung der Arbeitsgemeinschaft Exogen-Allergische Alveolitis, Freyburg/Unstrut, 12.-14. September 2003

\title{
Kefir verträglich bei Laktoseintoleranz
}

E ermentierte Milchprodukte werden - bei Laktoseintoleranz im allgemeinen besser vertragen als reine Milch, besonders günstig ist offenbar Kefir: Ernährungswissenschaftler der Ohio State University hatten 15 Erwachsenen mit Laktoseintoleranz nach 12-stündigem Fasten 20 mg Laktose entweder in Form von Milch, Kefir oder Joghurt gegeben. Die Verstoffwechslung des Milchzuckers wurde über den Wasserstoff in der Atemluft quantifiziert, die Probanden

\section{Vergessliche Patienten}

$P$ atienten behalten nur 20\% von dem, was Ärzte ihnen erklären. Und von dem Wenigen, was sie zu erinnern meinen, ist auch noch fast die Hälfte falsch. Das berichtet zumindest ein niederländischer Wissenschaftler, der in verschiedenen Ländern Patienten nach einem Krankenhausaufenthalt befragt hat. Dass die medizinischen Informationen so schnell in Vergessenheit geraten, liegt seiner Ansicht nach nicht nur an den Patienten (vor allem hohes Alter und emotionaler Stress wirken sich nachteilig aus), sondern auch an den Ärzten, die zu wenig anschaulich erklären. Deswegen der Rat an die Kollegen, sich möglichst einfach und klar auszudrücken und das beurteilten außerdem die individuelle Bekömmlichkeit der Mahlzeiten. Der reine Kefir wurde ähnlich gut wie Joghurt und signifikant besser als Milch vertragen. Die Autoren nehmen an, dass einige der in Kefir enthaltenen Enzyme die Magenpassage unbeschadet überstehen und dann für die Laktoseverdauung im Darm zur Verfügung stehen.

\section{Hertzler SR et al. J Am Diet Assoc 2003;} 103: 582-7

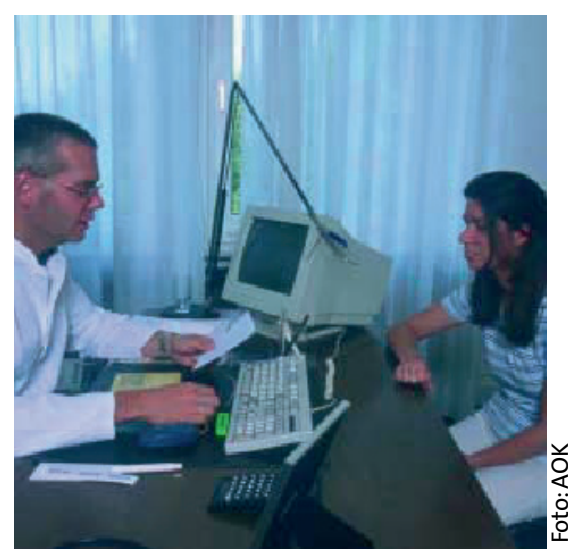

Wichtigste zuerst zu sagen und vielleicht sogar aufzuschreiben. Besonders gut behalten die Patienten übrigens das, was mit ihren bestehenden Ansichten übereinstimmt.

$D E$

Kessels RP. J R Soc Med 2003; 96: 219-22

\section{Evolution der Düfte}

$\mathrm{N}$ ur wenige Parfums schaffen es, über Jahrzehnte hinweg in der Gunst der Frauen zu bleiben - dazu gehört der Klassiker Chanel No. 5. Da wunderten sich die Zuhörer beim 19. Fortbildungskongress in Davos schon, als Prof. Dr. Norbert Reider aus Innsbruck das Geheimnis des Erfolgs lüftete: Selbst eingeführte Marken werden in ihrer Zusammensetzung ständig dem Zeitgeist angepasst. Das heutige Chanel No. 5 entspricht also keineswegs mehr der 1923 von Coco Chanel kreierten Duftkombination gleichen Namens. Prompt konnten das Allergikerinnen im Publikum bestätigen: Jahrelang hatten sie sich problemlos in ihren Lieblingsduft gehüllt, doch plötzlich vertrugen sie ihn nicht mehr.

FK

\section{Reider N. 19. Fortbildungskongress}

„Fortschritte der Allergologie, Immunologie und Dermatologie“, Davos, 17.-20. September 2003

\section{Hormonabhängiges Nasenleid}

_ iner ungewöhnlichen Fragestellung gingen mexikanische Forscher nach: Sie wollten wissen, ob die unterschiedlichen Hormonspiegel während des Zyklus Auswirkungen auf die $\mathrm{Na}$ senschleimhaut haben. Von 15 Frauen entnahmen sie Nasen- und Vaginalabstriche während Follikel- und Lutealphase und fanden eine signifikante Korrelation zwischen den zytologischen Veränderungen von Nasen- und Vaginalepithelien einerseits sowie diesen zytologischen Veränderungen und der Zyklusphase andererseits. Die Autoren hoffen durch ihre Untersuchungen hormonabhängige Nasensymptome wie veränderte Riechwahrnehmung, Nasenbluten oder Empfindlichkeit gegenüber Histamin demnächst günstig beeinflussen zu können.

Navarrete-Palacios E et al. Arch Otolaryngol Head Neck Surg 2003; 129: 460-3 